\title{
The Life Cycle Information Support Technologies of the Onboard Radio-Electronic Equipment of the Missile and Space Engineering
}

\author{
Sergey G. Kochuraa, Vadim N. Shkolny, \\ Sergey B. Suntsov ${ }^{\text {a }}$ Egor A. Morozova, \\ Oleg A. Klimkin ${ }^{\mathrm{a}}$ and Vadim M. Karaban*b \\ a"Information Satellite Systems" Academician M.F. Reshetnev \\ 52 Lenin Str., Zheleznogorsk, 662972, Russia \\ ${ }^{b}$ Tomsk State University of Control Systems and Radioelectronics \\ 40 Lenina, Tomsk, 634050, Russia
}

Received 31.03.2015, received in revised form 20.11.2015, accepted 24.12.2016

On the example of the onboard radio-electronic spacecraft's equipment creation are presented results of development and approbation of a technical and information solutions of "the electronic enterprise" of missile-space branch and the industry standard RD-134-0184-2010 "The methodical recommendations for implementation of information support technologies of the onboard radio-electronic equipment's creation of the missile and space engineering at all stages of life cycle" which includes recommendations about the organization of "the electronic enterprise" and to a choice program and hardware. Results of work are introduced in process of design of onboard radio-electronic spacecraft's equipment of the JSC "ISS" and allow to increase efficiency and competitiveness of the production, to reduce costs of purchase of program and technical providing, to reduce time of creation of onboard radio-electronic equipment of the missile and space engineering by 1,3 times, to reduce material expenses by 1,25 times.

Keywords: electronic enterprise, information support, life cycle, onboard radio-electronic equipment, spacecraft, missile and space equipment.

Citation: Kochura S.G., Shkolny V.N., Suntsov S.B., Morozov E.A., Klimkin O.A., Karaban V.M. The life cycle information support technologies of the onboard radio-electronic equipment of the missile and space engineering, J. Sib. Fed. Univ. Eng. technol., 2017, 10(3), 364-371. DOI: 10.17516/1999-494X-2017-10-3-364-371.

(c) Siberian Federal University. All rights reserved

* Corresponding author E-mail address: karaban_vm@mail.ru 


\title{
Технологии информационной поддержки
}

\section{жизненного цикла бортовой радиоэлектронной аппаратуры ракетно-космической техники}

\author{
С.Г. Кочура а, В.Н. Школьный \\ Е.А. Морозов ${ }^{\text {a }}$ О.А. Климкин ${ }^{\mathrm{a}}$, В.М. Карабан ${ }^{6}$

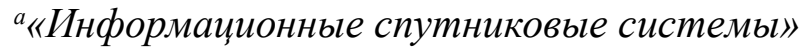 \\ имени академика М.Ф. Решетнёва \\ Россия, 662972, Железногорск, ул. Ленина, 52 \\ ${ }^{6}$ Томский государственный университет \\ систем управления и радиоэлектроники \\ Россия, 634050, Томск, пр. Ленина, 40
}

На примере создания бортовой радиоэлектронной аппаратуры (РЭА) космического аппарата (КА) представлены результаты разработки и апробациии технических и информационных решений «электронного предприятия» ракетно-космическойотраслии отраслевого стандарта РД-134-0184-2010 «Методические указания по внедрению технологий информачионной поддержки создания бортовой РЭА ракетно-космической техники (РКТ) на всех стадиях жизненного ичикла», который включает в себя рекомендации по организации «электронного предприятия» и выбору программных и аппаратных средств. Результаты работы внедрены в проиесс проектирования бортовой РЭА КА АО «ИСС» и позволяют повысить эффективность и конкурентоспособность своего производства, сократить затраты на закупку программного и технического обеспечения, время создания бортовой РЭА РКТ в 1,3 раза, материальные издержки в 1,25 раза.

Ключевые слова: электронное предприятие, информационная поддержка, жизненный ијил, бортовая радиоэлектронная аппаратура, космический аппарат, ракетно-космическая техника.

\section{Введение}

На предприятиях ракетно-космической отрасли накоплены сотни тысяч конструкторских, технологических, эксплуатационных документов, описывающих жизненный цикл тысяч изделий. Большая часть этих документов представлена на бумажных носителях информации, объединённых в огромные архивы предприятий. При этом в новых разработках широко используются современные средства проектирования и изготовления, применяющие электронные документы. Многообразие форматов электронных документов делает невозможным обмен информацией об изделиях РКТ как между различными предприятиями, так зачастую и внутри предприятий. Огромный объём информации требует внедрения современных средств управления данными. Одним из современных инструментов является внедрение технологии информационной поддержки наукоёмких изделий (ИПИ), которая подразумевает создание единого информационного пространства для всех участников жизненного цикла изделия, включая потребителей изделия [1,2].

Основная причина проблем внедрения ИПИ-технологий на предприятиях ракетнокосмической отрасли - отсутствие нормативной и методической документации, регламентирующей применение современных подходов к управлению данными.

$$
-365-
$$


Основной смысл технологии информационной поддержки жизненного цикла заключается в повышении конкурентоспособности продукции за счёт эффективного управления информационными ресурсами. Для достижения этого на предприятиях необходимо создавать единое информационное пространство, которое должно объединить всех участников процесса создания конечного продукта, в том числе бортовой РЭА, обеспечить надёжный процесс проектирования, хранения, обмена и повторного использования всех данных, создаваемых на любом этапе жизненного цикла.

\section{Создание и отработка прототипа «электронного предприятия»}

На примере создания бортовой РЭА КА были апробированы технические и информационные решения «электронного предприятия». Прототип «электронного предприятия», созданный в АО «ИСС», охватывает все этапы жизненного цикла создания бортовой РЭА (рис. 1). Для реализации жизненного цикла бортовой РЭА РКТ прототип «электронного предприятия» состоит из следующих участков (направлений работ):

- разработка электронной части бортовой РЭА;

- разработка конструкции бортовой РЭА;

- технологическая подготовка механической обработки;

- технологическая подготовка приборостроения;

- испытания бортовой РЭА;

- управление жизненным циклом создания бортовой РЭА.

Схема взаимодействия участков прототипа «электронного предприятия» приведена на рис. 2.

На участке разработки электронной части бортовой РЭА обеспечено выполнение следующих задач:

- разработка и моделирование электрических принципиальных схем [3, 4];

- проектирование программируемых логических интегральных схем;

- разработка топологии печатных плат (ПП), пред- и посттопологический анализ [3-6];

- разработка конструкции ПП, а также тепловой и механический анализы конструкции [7-9];

- анализ надёжности $[10,11]$.

Работа участка обеспечивается автоматизированным рабочим местом (АРМ) разработки электронного макета бортовой РЭА, которое в свою очередь состоит из рабочих мест: схемотехнического проектирования, топологического проектирования, теплового анализа, расчёта надёжности и локального хранилища данных.

На участке разработки конструкции бортовой РЭА возможно выполнение следующих задач:

- разработка конструкции приборов;

- разработка моточных изделий;

- разработка жгутов и кабелей [12];

- тепловой и механический анализ конструкции $[13,14]$.

Работа участка обеспечивается АРМ разработки конструкции бортовой РЭА. 
На участке технологической подготовки механической обработки выполняются следующие задачи:

- разработка технологических процессов механического участка со станками числовым программным управлением (ЧПУ);

- разработка и верификация управляющих программ для станков ЧПУ.

Работа участка обеспечивается АРМ технологической подготовки механической обработки корпусных деталей бортовой РЭА.

На участке технологической подготовки приборостроения реализуется выполнение следующих задач:

- разработка технологических процессов участка изготовления ПП;

- разработка управляющих программ для станков ЧПУ участка изготовления ПП;

- разработка управляющих программ для станков ЧПУ монтажного участка;

- разработка технологических процессов участка изготовления моточных изделий;

- разработка технологических процессов сборочного участка.

Работа участка обеспечивается АРМ технологической подготовки приборостроения, которое в свою очередь состоит из рабочих мест: разработки технологического процесса изготовления печатных узлов бортовой РЭА и разработки технологического процесса изготовления бортовой РЭА.

На участке испытаний бортовой РЭА реализованы задачи проведения:

- электрических испытаний ПП;

- электрических, механических, термовакуумных и др. испытаний бортовой РЭА.

Работа участка обеспечивается АРМ электрических испытаний бортовой РЭА, которое, в свою очередь, состоит из рабочих мест: испытания печатных узлов бортовой РЭА и испытания бортовой РЭА.

На участке управления жизненным циклом создания бортовой РЭА реализованы следующие задачи:

- управление жизненным циклом создания бортовой РЭА;

- хранение проектных данных;

- управление бизнес-процессами.

Работа участка обеспечивается АРМ управления жизненным циклом создания бортовой РЭА, которое в свою очередь состоит из рабочих мест: сервера системы управления базами данных (СУБД) и глобального хранилища проектных данных.

\section{Разработка отраслевого стандарта информационной поддержки}

На основе отработки принципов, заложенных в созданном прототипе «электронного предприятия», разработан и утверждён отраслевой НДС РД-134-0184-2010 «Методические указания по внедрению технологий информационной поддержки создания бортовой радиоэлектронной аппаратуры РКТ на всех стадиях жизненного цикла». РД-134-0184-2010 зарегистрирован в ЦКБС ФГУП «ЦНИИ машиностроения» и внесён в реестр за № 19816 от 28.09.2010. Данный документ содержит основные положения технологий информационной поддержки создания бортовой РЭА РКТ и определяет основные принципы создания и внедрения технологий ин-

$$
-367-
$$


формационной поддержки на предприятиях космического приборостроения, требования к автоматизированным рабочим местам разработки, подготовки производства, испытания и управления жизненным циклом бортовой РЭА, входящим в состав прототипа «электронного предприятия».

Данный документ содержит следующие обязательные разделы:

- рекомендации по организации «электронного предприятия»;

- рекомендации по выбору программных и аппаратных средств.

Раздел «Рекомендации по организации «электронного предприятия» содержит:

- описание жизненного цикла бортовой РЭА;

- типовую схему «электронного предприятия»;

- перечень рекомендуемых форматов данных, используемых в электронном документообороте;

- рекомендации по взаимодействию различных исполнителей в рамках «электронного предприятия».

Раздел «Рекомендации по выбору программных и аппаратных средств» содержит:

- рекомендации по составу и функциональному назначению АРМ, входящих в состав «электронного предприятия»;

- рекомендации по оптимальному подбору программных и аппаратных средств АРМ, обеспечивающих надежное функционирование «электронного предприятия».

В ходе работы над документом было проанализировано положение с внедрением технологий информационной поддержки на ряде ведущих предприятий отрасли, в том числе АО «ИСС», ОАО «НПЦ «Полюс», ФГУП «НПО имени Лавочкина», ФГУП «ГНПРКЦ «ЦСКБ Прогресс». Результат анализа был объединен в техническом предложении. Редакция нормативного документа рассмотрена предприятиям отрасли, рекомендованным Федеральным космическим агентством и ЦКБС ФГУП «ЦНИИ машиностроения». В качестве экспертов выступила такие ведущие предприятия отрасли предприятия, как ЦКБС ФГУП «ЦНИИ машиностроения», ФГУП «ПО «Полет», ФГУП «ЦНИИ «Комета», ФГУП «РНИИ КП», ФГУП «НИИ КП», ФГУП «НПО «Автоматика», ФГУП «НИИ ПМ», ФГУП «НПЦ АП», ФГУП «НИИ ТП», ОАО «НПО Электромеханики».

Все полученные замечания и предложения к первой редакции нормативного документа были учтены в окончательной редакции нормативного документа. Окончательная редакция нормативного документа согласована со следующими предприятиями отрасли: ЦКБС ФГУП «ЦНИИ машиностроения», ОАО «РКС», ФГУП «НПО «Автоматика», ОАО «НПО Электромеханики».

\section{Заключение}

Новизна предлагаемых технологий заключается в разработке методологии создания «электронного предприятия», принципов его функционирования, в объединении разнородных элементов информационных технологий, применяющихся на этапах проектирования, моделирования, конструирования, изготовления, испытаний и сопровождения бортовой РЭА КА на всех этапах жизненного цикла. Разрабатываемая технология информационной поддержки создания 
бортовой РЭА ориентирована на применение на всех предприятиях ракетно-космической отрасли, участвующих в цикле создания РЭА. Новизной разработки в том числе является разрабатываемая система управления жизненным циклом, включающая:

- единый банк проектов (хранилища);

- систему удаленного доступа к базам данных электрорадиоизделий, материалов, проектов;

- систему управления бизнес-процессами;

- правила и порядок унификации форматов данных при обмене документами и программного обеспечения, используемого при создании бортовой РЭА;

- нормативную базу по ИПИ-технологиям.

Разработанные в результате выполнения работ рекомендации по выбору программного и технического обеспечения технологий информационной поддержки, форматам обмена электронными данными позволят приборным предприятиям ракетно-космической отрасли повысить эффективность и конкурентоспособность своего производства, сократить затраты на закупку программного и технического обеспечения, время создания бортовой радиоэлектронной аппаратуры РКТ в 1,3 раза, материальные издержки в 1,25 раза.

Описанные технические и информационные решения, приведенные в данной статье, широко применяются на практике в процессе проектирования бортовой РЭА в АО «ИСС». Это позволяет не только снизить затраты при проектировании, но и обеспечить более сжатые сроки на этапе изготовления путем внедрения унифицированных процедур.

\section{Список литературы}

[1] Юткин А.В., Климкин О.А., Дзювина А.В. Внедрение информационных технологий при проектировании радиоэлектронной аппаратуры космического аппарата и тепловом анализе печатных плат. Вестник СибГАУ, 2009, 2(23), 161-166 [Yutkin A.V., Klimkin O.A., Dzyuvina A.V. The introduction of information technology in the design of electronics and spacecraft thermal analysis of printed circuit boards. Bulletin SibGAU, 2009, 2(23), 161-166 (in Russian)].

[2] Сунцов С.Б., Климкин О.А., Сарафанов А.В., Фень А.М., Худоногов Д.Ю. Инженерный анализ при сквозном автоматизированном проектировании радиоэлектронной аппаратуры модульной ракетно-космической техники. Технология машиностроения, 2011, 5, 54-56 [Suntsov S.B., Klimkin O.A., Sarafanov A.V., Fen A.M., Khudonogov D.Y. Engineering analysis of the throughaided design of electronic equipment modular rocket and space technology. Manufacturing Technology, 2011, 5, 54-56 (in Russian)].

[3] Сунцов С.Б., Карабан В.М., Климкин О.А., Зырин И.Д., Севастьянов Р.С., Краюхин А.С. Обзор возможностей систем автоматизированного проектирования для схемотехнического и топологического моделирования радиоэлектронной аппаратуры. Томск: ТУСУР, 2013. 86 с. [Suntsov S.B., Karaban V.M., Klimkin O.A., Zyrin I.D., Sevastyanov R.S., Krajukhin A.S. Overview of CAD systems for circuit and topological modeling of electronic equipment. Tomsk: TUSUR, 2013. 86 p. (in Russian)].

[4] Карабан В.М., Севастьянов Р.С., Сунцов С.Б. Методика схемотехнического и топологического моделирования радиоэлектронной аппаратуры средствами программного обеспечения Mentor Graphics. Томск: ТУСУР, 2014. 172 с. [Karaban V.M., Sevastyanov R.S., Suntsov S.B. 
Methods of circuit and topological modeling of electronic equipment via software Mentor Graphics. Tomsk: TUSUR, 2014. 172 p. (in Russian)].

[5] Зырин И.Д., Карабан В.М., Морозов Е.А., Сунцов С.Б. Анализ целостности сигналов универсального электронного модуля бортовой радиоэлектронной аппаратуры космического назначения. Известия вузов. Физика, 2011, 54, 10/2, 91-96 [Zyrin I.D., Karaban V.M., Morozov E.A., Suntsov S.B. Analysis of the signal integrity of the universal electronic module on-board electronics for space purposes. Proceedings of the universities. Physics, 2011, 54, 10/2, 91-96 (in Russian)].

[6] Карабан B.M., Зырин И.Д. Методы снижения паразитной связи между проводниками. Технологии электромагнитной совместимости, 2013, 3(46), 68-78 [Karaban V.M., Zyrin I.D. Methods to reduce the parasitic relationship between conductors. EMC Technology, 2013, 3(46) 68-78 (in Russian)].

[7] Карабан В.М., Сухоруков М.П., Морозов Е.А. Математические модели многослойных печатных плат для теплового моделирования электронных устройств и систем. Доклады $T У$ СУР, 2013, 3(29), 170-174 [Karaban V.M., Sukhorukov M.P., Morozov E.A. Mathematical models of multilayer printed circuit boards for thermal simulation of electronic devices and systems. Reports TUSUR, 2013, 3(29), 170-174 (in Russian)].

[8] Сунцов С.Б., Карабан В.М., Сухоруков М.П., Морозов Е.А. Создание упрощённой тепловой модели унифицированного электронного модуля. Известия вузов. Физика, 2012, 55, 9/3, 114-119 [Suntsov S.B., Karaban V.M., Sukhorukov M.P., Morozov E.A. Creating a simplified thermal model of the unified electronic module. Proceedings of the universities. Physics, 2012, 55, 9/3, 114-119 (in Russian)].

[9] Карабан В.М., Зырин И.Д., Смолякова Е.Ф. Разработка новой несущей конструкции печатных плат, а также её механический, тепловой анализ для электронных модулей космического применения. В мире научных открытий, 2014, 4(52), 219-230 [Karaban V.M., Zyrin I.D., Smolyakova E.F. Development of a new PCB supporting structure, as well as its mechanical, thermal analysis of space applications for electronic modules. In the world of scientific discoveries, 2014, 4(52) 219-230 (in Russian)].

[10] Сунцов С.Б., Алексеев В.П., Карабан В.М., Пономарёв С.В. Прогнозирование надёжности узлов и блоков радиотехнических устройств космического назначения на основе моделирования напряженно-деформируемых состояний. Томск: ТУСУР, 2012. 114 с. [Suntsov S.B., Alekseev V.P., Karaban V.M., Ponomarev S.V. Reliability Prediction of units and blocks of radio devices for space application-based simulation of the stress-deformed state. Tomsk: TUSUR, 2012. 114 p. (in Russian)].

[11] Сунцов С.Б., Карабан В.М., Сухоруков М.П., Морозов Е.А. Исследование влияния угла изгиба и сглаживания печатного проводника электронного модуля на его надёжность (долговечность). Известия вузов. Физика, 2012, 55, 7/2, 124-129 [Suntsov S.B., Karaban V.M., Sukhorukov M.P., Morozov E.A. Investigation of the effect of smoothing and bending angle of the electronic module printed conductor on its reliability (durability). Proceedings of the universities. Physics, 2012, 55, 7/2, 124-129 (in Russian)].

[12] Бутин А.М., Дубровский Е.Ю., Климкин О.А., Добышев Е.В., Сунцов С.Б. Организация автоматизированного проектирования и электрического контроля бортовой кабельной сети космического аппарата в АО «ИСС». Наукоемкие технологии, 2015, 16, 3, 14-16 [Butin A.M., 
Dubrovsky E.Y., Klimkin O.A., Dobysh E.V., Suntsov S.B. Organization of computer-aided design and electrical control board spacecraft cable network in the JSC «ISS». High Technologies, 2015, 16, 3, 14-16 (in Russian)].

[13] Сунцов С.Б., Карабан В.М., Сухоруков М.П., Морозов Е.А. Численное моделирование напряженно-деформированного состояния унифицированного электронного модуля. Известия вузов. Физика, 2012, 55, 9/3, 120-125 [Suntsov S.B., Karaban V.M., Sukhorukov M.P., Morozov E.A. Numerical simulation of the stress-strain state of the unified electronic module. Proceedings of the universities. Physics, 2012, 55, 9/3, 120-125 (in Russian)].

[14] Сунцов С.Б., Карабан В.М., Сухоруков М.П., Морозов Е.А. Параметризация размещения унифицированных электронных модулей в составе бортовой РЭА КА с позиций управления температурными режимами. Известия вузов. Физика, 2012, 55, 7/2, 129-134 [Suntsov S.B., Karaban V.M., Sukhorukov M.P., Morozov E.A. Parameterization accommodation unified electronic modules in the on-board electronics of spacecraft with thermal management positions. Proceedings of the universities. Physics, 2012, 55, 7/2, 129-134 (in Russian)]. 